\title{
Complementary exams in the diagnosis of american tegumentary leishmaniasis
}

\author{
Ciro Martins Gomes ${ }^{1}$ \\ Orlando Oliveira de Morais ${ }^{1}$ \\ Ana Maria Roselino ${ }^{2}$
}

\author{
Natália Aparecida de Paula ${ }^{2}$ \\ Killarney Ataíde Soares ${ }^{1}$ \\ Raimunda Nonata Ribeiro Sampaio ${ }^{1}$
}

DOI: http://dx.doi.org/10.1590/abd1806-4841.20142389

\begin{abstract}
The diagnosis of American Tegumentary Leishmaniasis is a difficult but essential task when considering the high toxicity profile of the drugs available. Since the discovery of its etiologic agent, numerous diagnostic tests have been developed. None of the tests available today can be considered as the gold standard, since they do not add enough accuracy for the disease detection. Good epidemiological and clinical knowledge of the disease are fundamental precepts of the dermatology practice and precede the rational use of existing diagnostic tests. In this article we aim, through extensive literature review, to recall fundamental concepts of any diagnostic test. Subsequently, based on this information, we will weave important comments about the characteristics of existing diagnostic tests, including immunological tests such as Montenegro's skin test, serology and detection of parasites by direct examination, culture or histopathology. Finally we will discuss the new technologies and options for the diagnosis of Cutaneous Leishmaniasis. The molecular biology technique is considered a promising tool, promoting the rapid identification of the species involved. We also aim to educate dermatologists about a disease with high morbidity and assist in its difficult recognition.
\end{abstract}

Keywords: Dermatology: Diagnosis; Leishmaniasis, mucocutaneous; Molecular biology; Polymerase chain reaction; Serologic tests

\section{HISTORY}

Historical documents refer to American Tegumentary Leishmaniasis (ATL) in ancient times. Archaeological studies of the pre-Columbian era developed in Peru revealed mutilated human figures in ceramics, currently accredited to ATL, but which were for some years, confused with the clinical presentation of syphilis. ${ }^{1}$ The description of cases of uncertain etiology lasted until the early $20^{\text {th }}$ century, before the identification of the agents of the "Oriental button" by Wright in 1903, and the detection by Lindemberg and Carini \& Paranhos in 1909, of the causative agent of epidemic ulcers, observed during the railway construction in Northwest Bauru (São Paulo - Brazil). This brief report demonstrates the difficulty experienced by great scientists in the characterization of ATL and its etiological agent. ${ }^{1}$

The year 2012 represented a milestone in the history of leishmaniasis, celebrating the centennial of the announcement of the discovery of treatment with tartar emetic by Gaspar Vianna. This fact assumes great importance if we consider that the current first- line treatment of this disease still has relatively high levels of toxicity. ${ }^{2,3}$ This report highlights the need for an accurate diagnosis and also for advances in research aimed at the early identification of the etiologic agent of ATL.

\section{PRESENT SITUATION}

The remarkable population and economic growth in Brazil comes with new dilemmas concerning public health, which need urgent solutions. The uncontrolled expansion of urban boundaries is accompanied by the appearance of numerous pathologies, previously restricted to activities in areas of native forest. Prompt diagnosis and treatment of these diseases are crucial tasks, not always feasible, due to their intrinsic complexity and frequent lack of investment.

ATL is a mucocutaneous, infectious, parasitic and vector-borne disease, caused by protozoa of the genus Leishmania. Currently, it is considered a neglected disease. Epidemiological data point to an alarming

Received on 24.12 .2012

Approved by the Advisory Board and accepted for publication on 25.02.2013

* Work performed at the Hospital Universitário de Brasília - Universidade de Brasília (UNB-HUB) - Brasília (DF), Brazil.

Financial Support: Foundation for the Support of Teaching, Research and Assistance at Hospital das Clínicas da Faculdade de Medicina de Ribeirão Preto -

Universidade de São Paulo (HC-FMRP-USP -FAEPA) and Decanato de Pesquisa e Pós-graduação (DPP) - Universidade de Brasília - UNB.

Conflict of Interest: None.

Universidade de Brasília (UnB) - Brasília (DF), Brazil.

Universidade de São Paulo (USP) - Ribeirão Preto (SP), Brazil.

(C2014 by Anais Brasileiros de Dermatologia

An Bras Dermatol. 2014;89(5):701-11. 
increase in its incidence. ${ }^{4}$ This fact is due to the increasing human contact with wild environments, which are rich in parasitic reservoirs. Deforestation and uncontrolled urbanization are the main causal factors of this expansion.

The diagnosis of ATL is a difficult task. The tests currently available do not add enough accuracy to be considered the gold standard. For this reason, we use a combination of epidemiological, clinical and laboratory data (immunological and parasitological examinations) to reach the final diagnosis. ${ }^{4}$ Despite their availability, more accurate tests require technical training, not always existent in the most remote locations. Because of this limitation, in Brazil, many suspected cases are still receiving treatment based solely on clinical and epidemiological aspects. This is alarming, since the toxicity profile of existing drugs still requires careful monitoring. ${ }^{5,6,7}$

The main diagnostic tests use the detection of cellular or humoral immune responses to Leishmania infection, plus the presence of the parasite itself or its genetic material. ${ }^{8}$ Tests that detect the immune response generally exhibit good sensitivity, but poor specificity. The opposite happens with tests that aim to visualize the parasite, which have high specificity and low sensitivity. Molecular biology is a promising tool for adding adequate sensitivity and specificity, however its use is limited by the need of specialized centers to execute the technique.

Diagnostic criteria for ATL have not been homogeneously defined. Therefore, complementary exams that help diagnose it are desirable, since this is a disease in evident expansion. ${ }^{9}$ We will address below the main strategies to diagnose ATL.

\section{EPIDEMIOLOGIC CRITERIA}

Obtaining epidemiological data is the first step when there is a diagnostic suspicion of ATL. A history of traveling to areas of native forest or other endemic areas is considered relevant. ${ }^{10}$ The patient should be asked about leisure activities, work and habitat.

The assessment of epidemiological criteria becomes even more complicated when considering the uncontrolled urban expansion that occurs in South America, in view of the reports about urban transmission of ATL. ${ }^{11}$ For these reasons, if there is a compatible dermatological presentation, the lack of history of traveling to areas of native vegetation should not exclude the diagnosis of ATL.

Judging by the epidemiology of the species found, one can also try to infer a correlation between the clinical form of leishmaniasis and the probable site of infection. The species L. (V.) braziliensis and L. (L.) amazonensis are present throughout the Brazilian territory in a proportion of $80 \%$ and $20 \%$ of cases, respec- tively, while species such as L. (V.) guyanensis are more restricted to the north part of the country. ${ }^{4,12,13}$

\section{CLINICAL DIAGNOSIS}

The term ATL covers a wide clinical spectrum of manifestations, according to several characteristics of the host and the causative agent. ${ }^{4}$ Clinical examination, despite not giving a definite diagnosis, is a useful tool to every dermatologist, especially in defining which diagnostic tests should be required. Considering which area of skin is affected, ATL can be classified as cutaneous, mucosal or mucocutaneous. Additional criteria, such as medical history, time of evolution, distribution, extent of lesions and host immunity, ${ }^{14,15}$ will be addressed in the following classifications regarding the utility of various diagnostic tests:

\section{Localized Cutaneous Leishmaniasis}

The first sign of the localized cutaneous form is the appearance of an erythematous spot at the site of a mosquito bite, after an incubation period ranging from 2 weeks to 3 months. ${ }^{9}$ This spot evolves into a papule, that progressively ulcerates over a period of 2 weeks to 6 months (Figures 1 and 2). ${ }^{4}$ The typical lesion is a round or oval painless ulcer, located on exposed skin areas. ${ }^{16}$ Although the ulcerated form comprises the vast majority of ATL cases, the disease can evolve with indeterminate clinical features. ${ }^{17}$

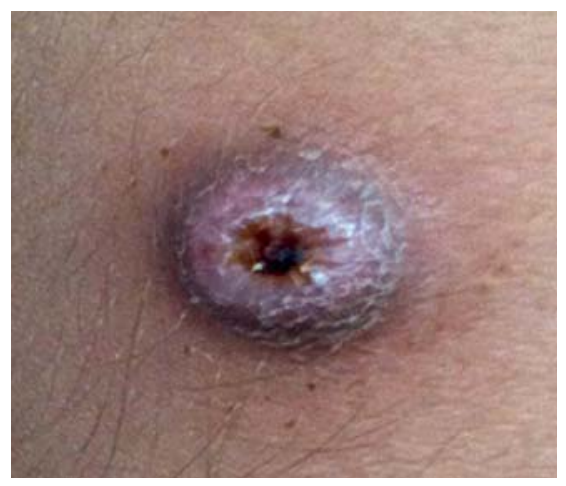

Figure 1: Initial clinical lesion, with o n e - m on th evolution, in a case of localized cutaneous leishmaniasis. Patient evolved with ulceration and development of a typical ATL cutaneous lesion

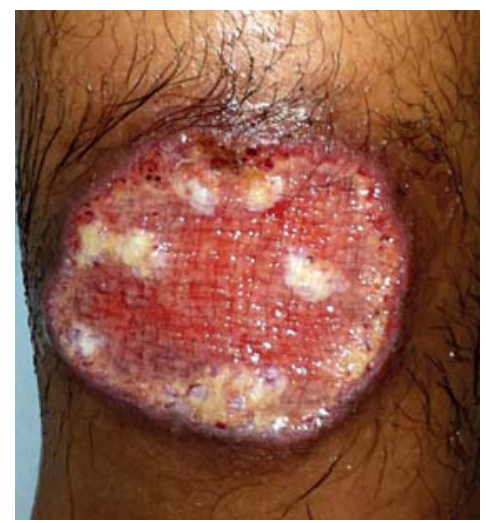

FIGURE 2:

ATL ulcer with elevated borders: evolution of the case after five months. 
Exceptionally, other types of localized cutaneous lesions may be found. It is important to mention the verrucous lesions that make differential diagnosis with deep mycoses and mycobacterioses, classically referred to by the acronym PLSCT (paracoccidioidomycosis, leishmaniasis, sporotrichosis, chromomycosis and tuberculosis). Another important example is the disease form that evolves with lymphangitis, combined or not with primary cutaneous lesions, a presentation hardly differentiated from sporotrichosis by clinical examination.

Leishmaniasis recidiva cutis is yet another manifestation of localized cutaneous leishmaniasis. It is characterized by the appearance of papules, usually on the periphery of an already healed ulcer. This form tends to appear two years after the clinical cure of ATL following poor treatment or lack thereof..$^{18}$ The fact that it can be considered a differentiated clinical form of ATL is controversial, but such lesions as described above deserve special attention, indicating a possible treatment resistance.

\section{Disseminated Cutaneous Leishmaniasis}

It is a rare form of ATL characterized by the appearance of at least 10 lesions, which may be papular, disseminated acneiform, ulcerated, with a high incidence of mucosal involvement. ${ }^{19}$ It is believed that, after the appearance of the primary lesion, an hematogenic or lymphatic dissemination occurs in patients with relative cellular immunodeficiency against Leishmania. ${ }^{20}$ This presentation may be accompanied by systemic manifestations such as fever, malaise, myalgia and weight loss. ${ }^{19}$

\section{Diffuse Cutaneous Leishmaniasis}

The diffuse form of ATL occurs in patients with impaired cellular immune response, necessary to fight the infection. In Brazil, it is caused by L. (L.) amazonensis. ${ }^{21}$ This clinical condition is characterized by nodular or plaque lesions, rarely ulcerated, extensive and diffuse. ${ }^{22}$ Affected patients present Montenegro skin test (MST), in general, with negative or weak reactions. ${ }^{23}$

\section{Mucosal Leishmaniasis}

The mucosal form tends to affect individuals with improperly treated cutaneous form, preceded by hematogenic dissemination of the parasite. Other factors may also be associated with mucosal involvement such as the host's immunity, male gender, extensive primary lesions or multiple lesions above the pelvic waist, primary lesion persisting over a year and malnutrition. ${ }^{24}$

It is characterized by mucosal infiltration, which may be associated to deformities and destruction of facial structures, especially the nasal septum, and more rarely the oral mucosa or oropharynx. ${ }^{4,25}$ (Figure 3 ) It represents a form of ATL that is difficult to diagnose, especially because of the challenge of obtaining biological samples for laboratory tests. The mucosal form is preferably due to $L$. (V.) braziliensis, although $L$. (L.) amazonensis may, rarely, represent the causal agent. ${ }^{26}$

\section{Unapparent infection}

The silent infection is considered as a simple contact with the parasite or a Leishmania infection without the development of apparent illness or the characteristic scar. It should be suspected in individuals coming from endemic areas and it is based on positive serological tests and MST. There is no consensus about the real meaning of this classification or on the routinely adoption of immunological tests, since it is not possible to predict its evolution towards clinical disease, and also because of the large number of false positive results obtained from these tests. ${ }^{27}$ Patients with isolated positivity for the aforementioned immunological tests should be carefully evaluated, especially for the presence of mucosal lesions.

\section{ATL associated to HIV infection}

ATL emerges as an opportunistic disease in HIV-infected patients, being reported by some authors as a possibly AIDS-defining illness. ${ }^{28}$ The current trend towards ruralization of HIV infection, as well as the concomitant urbanization of leishmaniasis in Brazil, are important indicators of the increased incidence of these cases. Co-infection of HIV / Leishmania alters the clinical course of ATL, justified by a heavy blow to the Th2 immune pole. This increases the susceptibility of the host to infection and is responsible for the development of anergic forms of ATL. ${ }^{29}$ This situation is a problem for the public health sector, since it is linked to greater diagnostic challenges, poorer prognosis and higher recurrence rates.

\section{Cutaneous involvement in visceral Leishmaniasis \\ Although the description of the visceral form of leishmaniasis is not the object of this review, reports of}

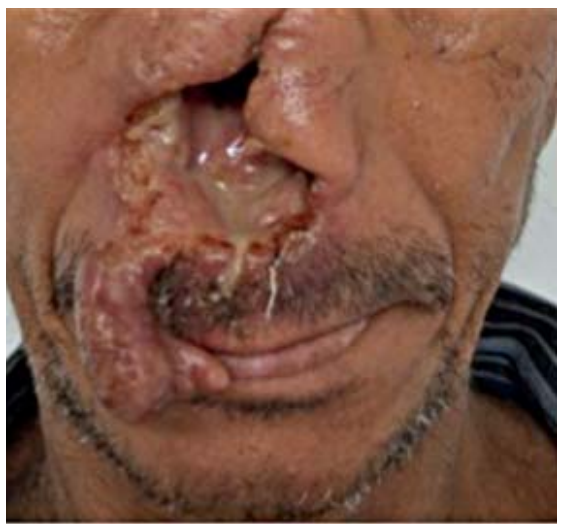

FIGURE 3: Case of cutaneous leishmaniasis with 10 years of evolution. An intense destruction of the nasal septum can be observed. This case represents a severe unusual clinical lesion, however it illustrates the potential severity of mucosal leishmaniasis. 
skin lesions associated with kala-azar have been escalating. ${ }^{30}$ This form of the disease, also known as post-Kalaazar cutaneous leishmaniasis, may appear clinically as macules, papules or skin nodules arising after the cure of visceral leishmaniasis. ${ }^{31}$ This association has been described as a result of the spread of visceral leishmaniasis in immunocompromised patients. It represents a form that is hard to diagnose, so that tests that detect the parasite or its genetic material, become essential.

\section{LABORATORY DIAGNOSIS}

\section{CHARACTERISTICS OF A DIAGNOSTIC TEST}

Before starting detailed explanations on specific diagnostic strategies for ATL, it is important to note the features inherent to any diagnostic test. ${ }^{32}$

- Sensitivity: Proportion of individuals in which the diagnostic test will be positive, considering all patients with the disease. It can also be seen, as the probability of a test being positive if the disease is present. It measures the power of a test to diagnose the disease. In the case of a test with high sensitivity, negative test results are highly reliable, however, this characteristic does not guarantee that all positive tests will be truly positive.

- Specificity: Proportion of individuals for whom the diagnostic test will be negative, considering all patients without the disease. It can also be seen, as the probability of a test being negative in the absence of the disease. A high specificity test does not guarantee that all individuals with a particular disease will be identified, but a positive result is usually reliable.

Sensitive tests are often used in cases of severe illness, in which a false negative result would be very harmful. It is also an appropriate test for rare diseases; those in the early stages and also in situations where one wants to perform a population screening. ${ }^{32}$ Specific tests are useful in diseases with high social impact in which a false positive result can be very detrimental, or those where the treatment may result in substantial risk. It can also be used as a complementary test to confirm the diagnosis. ${ }^{32}$

- Positive predictive value: Refers to the proportion of patients with true positive results among all positive results. It can be considered as the probability of the disease being present in the case of a positive test result.

- Negative predictive value: Refers to the proportion of patients with true negative results among all individuals with negative tests. It can also be considered the probability that the disease is absent if the test was negative.

- Accuracy: It measures the precision of a diagnostic test, weighting and considering the values of sensitivity and specificity. This estimates how much a test approaches the gold standard for the diagnosis of a disease.

Due to the absence of a gold standard test for ATL diagnosis, it is important to mention some strategies for combining diagnostic tests:
- Serial testing: Serial testing is generally used when the test has little specificity if performed alone. In this case, after the observation of a positive result, a new confirmatory test will be executed. This method aims to increase the specificity and positive predictive value of a test.

- Parallel testing: this strategy is used in situations where a rapid diagnosis is necessary, despite the higher cost to perform two tests simultaneously. Parallel testing increases the sensitivity and negative predictive values of the diagnostic process. Based on these concepts we will address the features of the main tests used in diagnosing ATL.

\section{MONTENEGRO SKIN TEST}

MST, also known as leishmanin skin test, evaluates the late cellular hypersensitivity response. The test consists of an intradermal injection of a solution containing an antigenic preparation of promastigotes (Figure 4). It tends to show positive results within 3 months of infection, not having however frequent positivity in acute infections and in anergic forms as disseminated cutaneous leishmaniasis.

A result is considered positive with the appearance of a hardened papule, equal or greater than $5 \mathrm{~mm}$ after 48 hours of application on the anterior forearm. It is a test of high sensitivity, low cost and minimally invasive. According to studies, sensitivity can reach over $90 \% .{ }^{33,34}$ This positivity is directly proportional to the length of disease evolution, so low values such as $30 \%$ reported in a few studies, can be explained by the premature execution of the test, when the cellular immune response is not yet complete. ${ }^{33.34}$ Specificity varies around $75 \%{ }^{35}$ The relatively low specificity can be explained by the overall large number of false positive results in cases of unapparent infection and cross-reactivity with some pathologies such as Chagas disease, subcutaneous mycoses, tuberculosis and lepromatous leprosy, as well as technical problems. ${ }^{36}$ The measurement is usually performed using a ballpoint pen, starting from the normal skin zone until the hardened area. Some authors have pro-

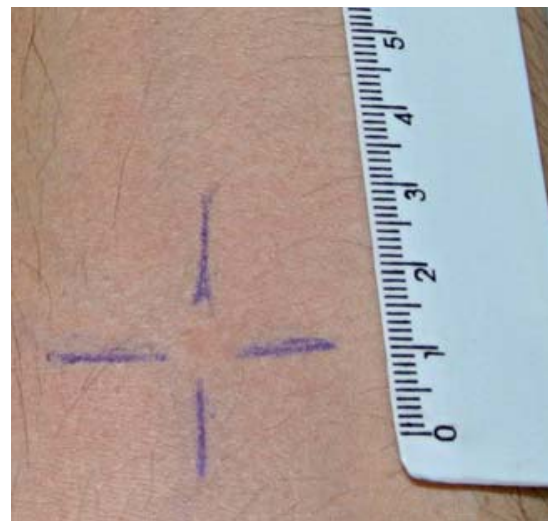

FIGURE 4:

Montenegro skin test: intradermal application of a solution containing antigenic preparation of promastigote forms of Leishmania. The result should be evaluated within 48 hours with a ballpoint pen, being positive if the papule formed is equal or greater than $5 \mathrm{~mm}$ 
posed the documentation of results drawn with ballpoint pen and the subsequent application of paper soaked in alcohol. ${ }^{37}$ This method is expected to document the test results more reliably and facilitate their registration in the medical record.

\section{SEROLOGICAL TESTS}

There are many serological tests for the diagnosis of cutaneous leishmaniasis. Among these we can cite the indirect immunofluorescence assay (IFA), the enzyme linked immunosorbent assay (ELISA) and immunoblotting (Western blot) (Figure 5). The sensitivity and specificity of serologic tests shows great variability depending on the technique used and the presentation of the disease. They tend to have negative results within 3 months after the onset of the cutaneous form of the disease. IFA and ELISA tests are considered highly sensitive by most studies, reaching values greater than $90 \%{ }^{34,38,39}$ Methodological flaws and premature execution of these exams, in the first moments of infection, explain the few studies that attribute a low positivity rate to them. ${ }^{34,38,39}$ Tests tend to be more sensitive in infections caused by L. (V.) braziliensis compared to diseases caused by L. (L.) amazonensis. ${ }^{38}$

Using Western blot for diagnosis of leishmaniasis adds greater sensitivity to the process, sometimes reaching close to $100 \%$. However, it is a more costly exam that requires greater technical laboratory infrastructure, thus hindering its implementation as routine. ${ }^{39}$

As mentioned above, some authors consider serological tests as having limited use for ATL diagnosis. ${ }^{39,40}$ However, their results may be considered as diagnostic data to be added to physical examination and other available tests. These are minimally invasive exams that present, however, cross-reactions with other diseases, such as Chagas disease, paracoccidioidomycosis, pemphigus foliaceus, and deep mycoses, thus explaining their low specificity. These tests are widely used tools in epidemiological studies.

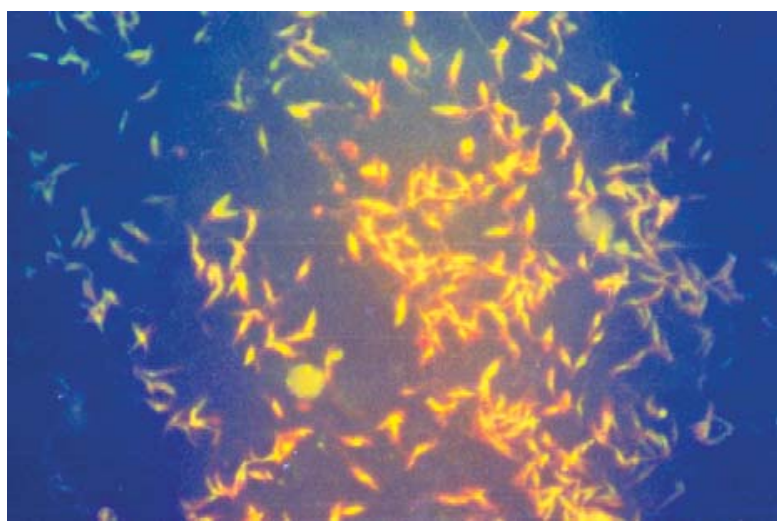

FIGURE 5: Indirect search for antibodies. Positive result with fluorescence of the promastigote forms of Leishmania
Some authors recommend their use as a tool to monitor cure, a complementary aid to physical examination, considering that after treatment their values are expected to remain stable or even decrease. ${ }^{41}$ On the other hand, the increase of values should warn to the possibility of relapse, a fact to be appraised in conjunction with clinical evaluation, the latter still considered the main form of relapse assessment in this disease.

\section{DIRECT EXAM}

The execution of direct exam has several technical variations. To collect the material, some strategies may be used, such as scrapping by scalpel or brush, needle aspiration, imprint of excised fragments on slides and washing of oral or nasal mucosa. ${ }^{42,43}$ Stains like Wright, Giemsa and Papanicolau can be used.

It has the advantage of being a low-cost test that when positive may give a definite diagnosis, presenting as a useful tool for the early initiation of treatment. It has a variable sensitivity, from $15-70 \%$ depending on how old the lesion is, and it is considered relatively low, especially in lesions with more than 3 months of evolution, and in chronic hyperergic forms of ATL. ${ }^{34,35,38}$ Although this method depends on the experience of the examiner, it has an almost complete specificity, since the finding of amastigotes virtually confirms the diagnosis. ${ }^{35}$ Few data concerning the influence of various types of collection are available. A recent study showed greater sensitivity for needle aspirate cytology $(89 \%)$ compared to scaling by scalpel $(80 \%)$ with statistically significant results. The specificity of the two methods remained similar. ${ }^{43}$

\section{HISTOPATHOLOGICAL EXAM}

Histopathological exam is an everyday tool in dermatology. The biopsy should be performed preferentially on the active border of the lesion and not in its center. ${ }^{44}$ Higher sensitivity of diagnosis can be achieved with the use of immunohistochemistry or immunocytochemistry. ${ }^{9,45}$ Visualization of amastigote forms is not usually easy, specially in chronic lesions. ${ }^{42,46}$

This method is less successful in visualizing, in great detail, the amastigote forms that can furthermore be mistaken for fungal elements of histoplasmosis or parasites of toxoplasmosis, as well as artifacts, explaining the low specificity of the test. ${ }^{42}$ (Figure 6) The classic histopathological findings consist in a non-specific granulomatous reaction, with an inflammatory infiltrate rich in plasma cells and lymphocytes. An exuberant pseudoepitheliomatous hyperplasia may occur, which leads to a differential diagnosis with squamous cell carcinoma (Figure 7). ${ }^{47}$ Particularly in mucosal leishmaniasis, the amastigote forms are very scarse. ${ }^{42}$ 


\section{CULTURE}

Several technical variations are described for carrying out cultures in ATL diagnosis. This procedure may be realized in vitro by microculture or traditional culture, as well as in vivo. Some of the traditional techniques for in vitro culture consist in seeding the material in Neal, Novy, Nicolle (NNN) solid phase or in a liquid medium such as Schneider's. (Figure 8) Traditional culture's sensitivity may vary between 40 to $75 \%$ and it has a nearly complete specificity, since the visualization of the seeded promastigote form is typical. ${ }^{35,44}$ Needle aspiration on the border of the lesion may provide material to be seeded in the aforementioned media. ${ }^{48,49}$

New microculture techniques that have been developed, demonstrate a higher diagnostic accuracy than that of traditional culture, besides needing a shorter incubation period to achieve its conclusion (an average of 2 days). ${ }^{50,51}$ It appears to be a less costly method than the traditional one, since it utilizes only a small quantity of the culture medium. ${ }^{52}$ It has, however, the disadvantage of producing only a small quantity of promastigote forms, which may hinder the execution of new experiments. ${ }^{35}$

In vivo culture requires a complex methodology, carrying risks of accidents by inoculation and demanding an experienced technician for its execution (Figure 9). This method is subject to ethical impediments and it is not commonly used in diagnostic routines. It is noteworthy that this is an important complementary tool, especially in dubious cases and during researches.

\section{MOLECULAR BIOLOGY}

The use of molecular biology in the diagnosis of leishmaniasis is considered a promising notion, because it allies at the same time, higher sensitivity and specificity in comparison to other tests described. ${ }^{53}$ It must be highlighted, however, that this test is not available in most reference centers.

Several types of sample may be used in order to extract genetic material to be analyzed by molecular biology tests. Among others are the fragments obtained from incisional biopsy either fresh, frozen or paraffin embedded; in addition to samples obtained from non-invasive procedures such as scarification of the lesion. Other mentioned techniques, as lesion imprint on filter paper have the advantage of an easy storage until the moment of DNA extraction and execution of the test (Figure 10). ${ }^{54,55,56}$ After the collection, the DNA can be extracted from cells through several laboratorial techniques, including by the use of commercially available kits.

After the extraction process, all DNA present in the sample is purified, ideally free of proteins and contaminant reagents. The amount of DNA is still
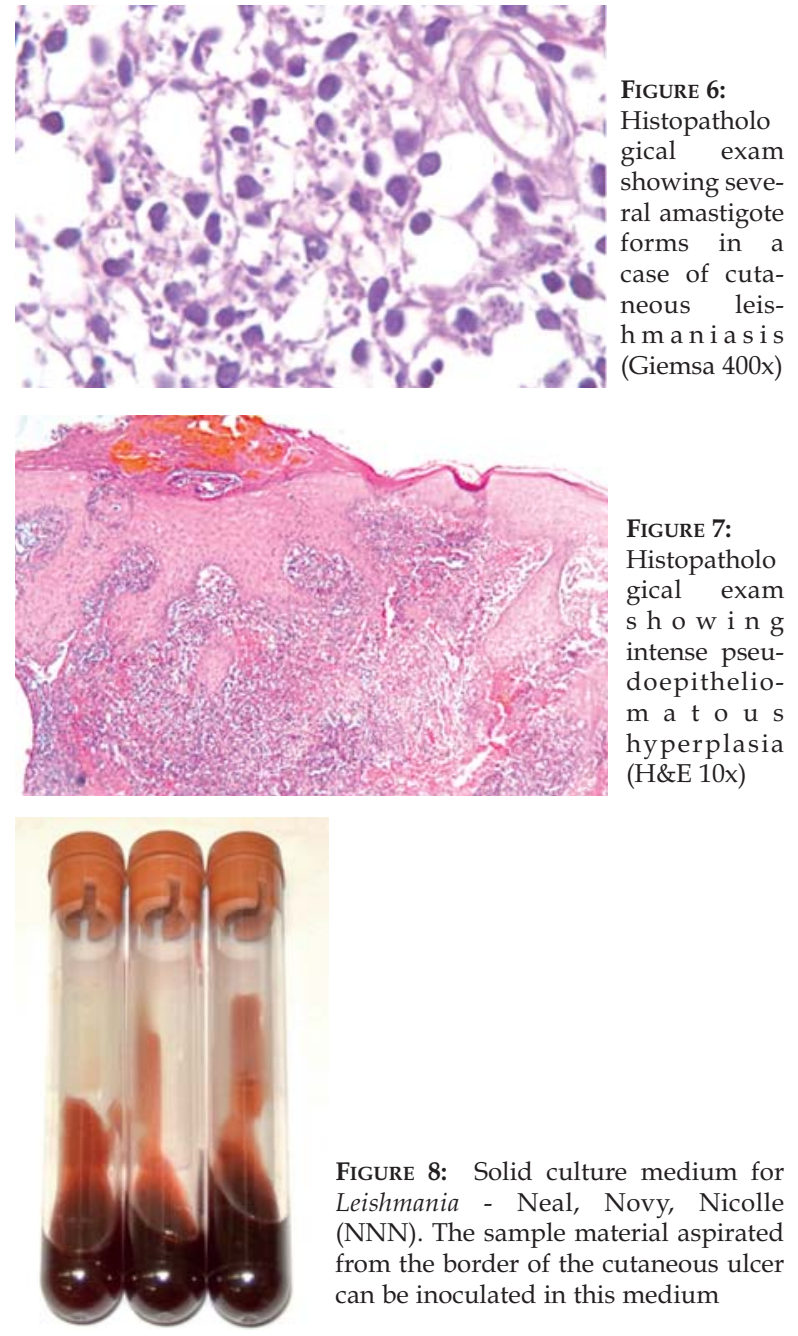

FIGURE 8: Solid culture medium for Leishmania - Neal, Novy, Nicolle (NNN). The sample material aspirated from the border of the cutaneous ulcer can be inoculated in this medium

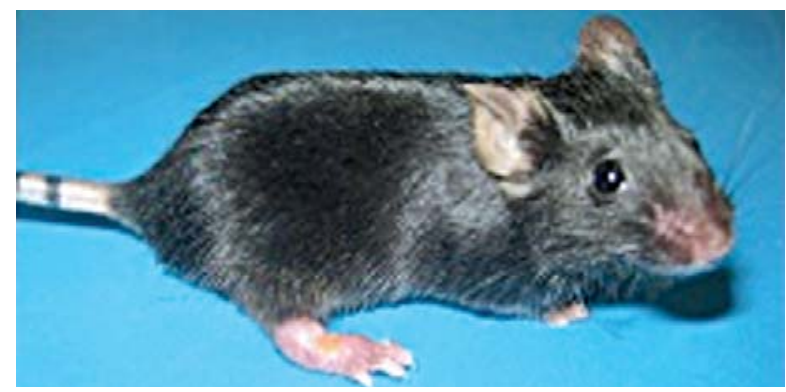

FIGURE 9: In vivo culture: C57BL/ 6 strain mouse, Mus musculus species, adult female infected subcutaneously on the right paw with $3.57 \times 10^{6}$ promastigotes of Leishmania (L.) amazonensis, in the metacyclic phase.

undetectable, and in order to identify remains of the parasite it is necessary that this DNA be amplified. ${ }^{54}$

In vitro DNA amplification is obtained through Polymerase Chain Reaction (PCR) technique, which consists in replicating small amounts of DNA (or RNA) by an enzyme in a reaction with cyclic temper- 
ature changes, simulating the physiological replication of DNA. This process consists of three phases described below: $:^{44,57}$

1. The extracted double-stranded DNA is separated in two simple strands, at 92 to 96 degrees Celsius, a process known as thermal denaturation. The single strands will be templates for the chain amplification of new strands.

2. The presence of oligonucleotides, known as primers or initiators, that bond to a specific target region of the template DNA at a temperature of 58 to 65 degrees Celsius is necessary to allow the amplification to begin in the template strand. This connection will be the primer for chain amplification.

3. Through a polymerase enzyme, new nucleotides are added to extend the primer sequence until the single strands are complemented, thus duplicating the initial DNA sample.

These three steps are repeated several times, and at each additional cycle, the freshly replicated molecules also become templates for new amplifications, multiplying exponentially the amount of DNA. These characteristics are responsible for the high sensitivity of this method, even if the initial amount of DNA extracted from the collected sample is small.

The last step consists in the analysis of the amplified product and its comparison to previously established controls. At the end of the PCR process, the target DNA is multiplied and to visualize this result it is necessary to perform an agarose or polyacrylamide gel electrophoresis (Figures 11 and 12).

This method has a variable detection rate, depending on the collection technique, extraction, purification and amplification of targeted DNA. Sensitivity may vary around $60 \%$, but it tends to reach higher values, often close to $100 \% .^{58,59}$

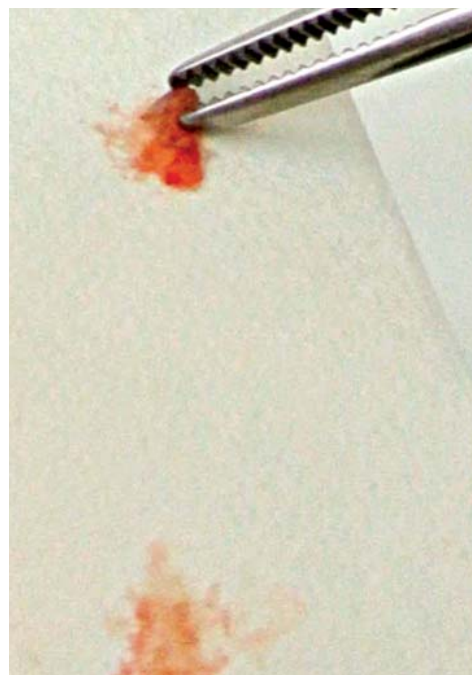

FigURE 10:

Collection technique of an imprint in paper filter of material from incisional biopsy. The collected material can be easily stored, sent for DNA extraction and polymerase chain reaction

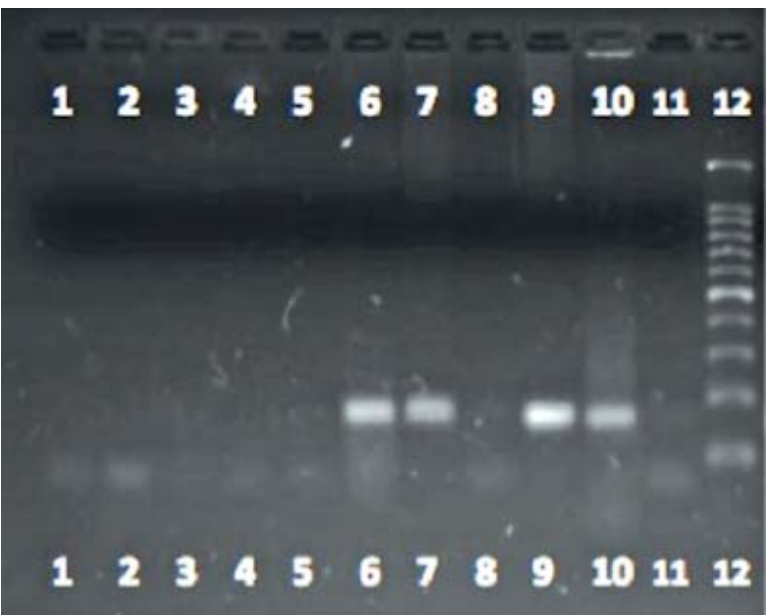

FIGURE 11: Agarose gel print of PCR amplified material showing positivity for Leishmania spp. Sample collected from a lesion, in a case of mucosal leishmaniasis, by paper filter imprinting (6) and nasal swab (7). Demonstration of positivity on incisional biopsy sample, in a case of cutaneous leishmaniasis (9). Positive control (10). Negative control (11). 100 bp molecular marker (12). Exam performed at the Dermatology Service Laboratory, HC-FMRP-USP, Ribeirão Preto, SP, Brazil

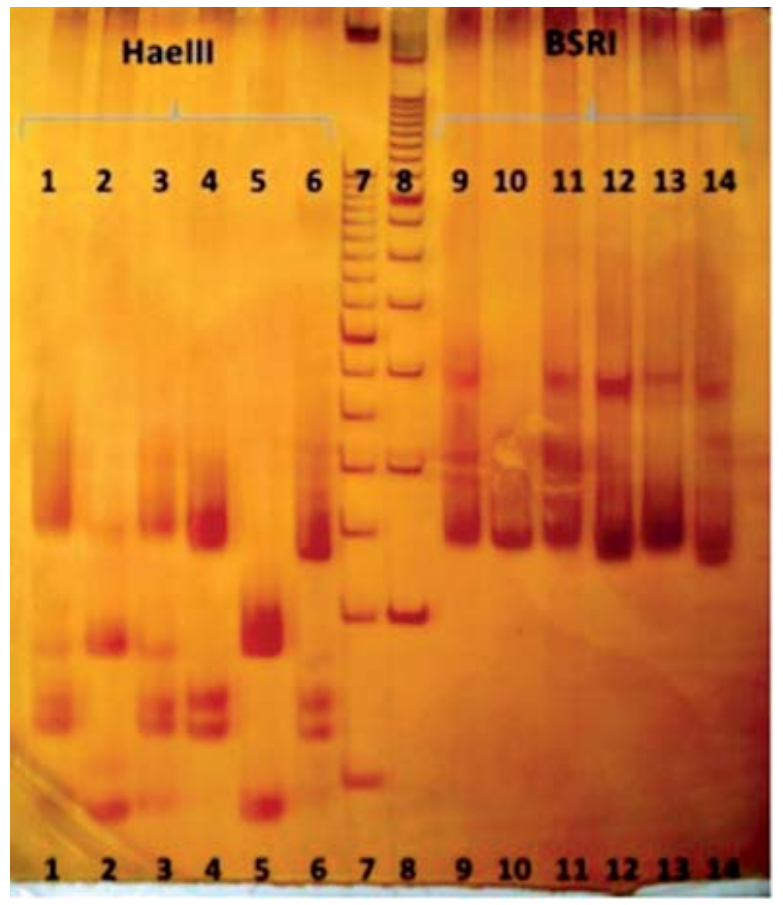

FIGURE 12: $10 \%$ acrylamide gel electrophoresis after enzymatic digestion of PCR amplified material - PCR-RFLP. Digestion by the enzyme HaeIII in species L. donovani (4); L. (V.) braziliensis (5); L (L.) amazonensis (6) kept in culture. Digestion by the enzyme BsrI in species L. donovani (12); L. (V.) braziliensis (13); L (L.) amazonensis (14) kept in culture. Depicts 50 bp and 100bp molecular markers respectively $(7,8)$. Exam performed at the Dermatology Service Laboratory, HC-FMRP-USP, Ribeirão Preto, SP, Brazil 
The addition of new steps to the reaction described above aggregates other properties to PCR. These advances nowadays enable new tools, such as the amplification of RNA fragments and the quantitative analysis of amplified products.

The method known as reverse transcriptase chain reaction (RT-PCR) consists in the amplification of RNA extracted from cells. To this end, the reverse transcriptase reaction is added to PCR, which converts RNA in complementary DNA, for its amplification by chain reaction. This technique permits the identification of the messenger RNA involved in several biological processes. It is a test with extremely high sensitivity, although it demands a state-of the art laboratorial structure to be executed.

Real-time PCR aggregates additional proprieties to the aforementioned technique. The amount of amplified material is monitored during the chain reaction process, i.e., in real time. Fluorochromes or probes, which connect to the replicated DNA and emit fluorescence, are employed. As the reaction progresses, the fluorescence increases permitting the quantitative analysis of DNA.

\section{SPECIES IDENTIFICATION}

Molecular biology also allows for the identification of the species responsible for the infection. This procedure is limited to research centers, but it can be extremely useful, especially in those rare clinical presentations such as diffuse or disseminated cutaneous leishmaniasis, since the mechanisms of immune escape are important factors in determining the clinical form. There are several ways to identify each species. Initially, primers with species-specific sequencing can be used in the chain reaction

\section{REFERENCES}

1. do Vale ECS, Furtado T. Tegumentary leishmaniasis in Brazil: a historical review related to the origin, expansion and etiology. An Bras Dermatol. 2005;80:421-8.

2. de Lima EB, Porto C, da Motta JOC, Sampaio RNR. Treatment of American cutaneous leishmaniasis. An Bras Dermatol. 2007;82:111-24.

3. de Lima MVN, de Oliveira RZ, de Lima AP, Cerino DA, Silveira TGV. American cutaneous leishmaniasis with fatal outcome during pentavalent antimoniate treatment. An Bras Dermatol. 2007;82:269-71.

4. Brasil. Ministério da Saúde. Secretaria de Vigilância em Saúde. Departamento de Vigilância Epidemiológica. Manual de Vigilância da Leishmaniose Tegumentar Americana. 2 ed. Brasília: Ministério da Saúde, 2007. 182p.

5. Wise ES, Armstrong MS, Watson J, Lockwood DN. Monitoring toxicity associated with parenteral sodium stibogluconate in the day-case management of returned travellers with New World cutaneous leishmaniasis. PLoS Negl Trop Dis. 2012;6:e1688.

6. Lima MI, Arruda VO, Alves EV, de Azevedo AP, Monteiro SG, Pereira SR. Genotoxic effects of the antileishmanial drug Glucantime. Arch Toxicol. 2010;84:227-32.

7. Sampaio RNR. Leishmaniose Tegumentar Americana: Diagnóstico e Tratamento. In: Lupi 0, Cunha PR, editores. Rotinas de Diagnóstico e Tratamento da Sociedade Brasileira de Dermatologia. Rio de Janeiro: AC Farmacêutica; 2012. p.379-87.

8. Zaghi D, Panosian C, Gutierrez MA, Gregson A, Taylor E, Ochoa MT. New World cutaneous leishmaniasis: current challenges in diagnosis and parenteral treatment. J Am Acad Dermatol. 2011;64:587-92.

9. Goto H, Lindoso JA. Current diagnosis and treatment of cutaneous and mucocutaneous leishmaniasis. Expert Rev Anti Infect Ther. 2010;8:419-33. described above.

PCR complementary tools are also useful. The method denominated as PCR-restriction fragment length (PCR-RFLP) is applied to confirm the nucleic acid fragments amplified by PCR technique (Figure 12). ${ }^{58}$ Digestive enzymes are used to cleave the DNA in specific sites, peculiar to certain species. Thus, the product of digestion is revealed and compared to other already known molecular profiles.

Other molecular methods such as multilocus enzyme typification and DNA sequencing may help identify the Leishmania species involved in the process. ${ }^{60}$ Genetic sequencing, although auspicious, consists in a highly expensive method, restricted to larger research centers, even though it is immensely useful to identify the implicated species. ${ }^{26}$

\section{CONCLUSION}

ATL diagnosis is a difficult yet essential task, considering the high toxicity profile of the drugs available for treatment. Since the discovery of the etiological agent, several diagnostic tests have been developed, however, none of the exams available nowadays can be considered the gold standard. A thorough epidemiological and clinical knowledge of the disease is crucial to the rational and concomitant use of such diverse diagnostic tools available. All dermatologists should have a deep knowledge of the inherent characteristics of any diagnostic test and be alert to the advent of new techniques such as molecular biology.

\section{AKNOWLEDGEMENTS}

We would like to thank Mr. Ricardo Fontoura de Carvalho for his contribution regarding the methods of in vivo culture of Leishmania. $\square$
10. Field V, Gautret P, Schlagenhauf P, Burchard GD, Caumes E, Jensenius M, al. Travel and migration associated infectious diseases morbidity in Europe, 2008. BMC Infect Dis. 2010;10:330

11. Gil JF, Nasser JR, Cajal SP, Juarez M, Acosta N, Cimino RO, et al. Urban transmission of American cutaneous leishmaniasis in Argentina: spatial analysis study. Am J Trop Med Hyg. 2010;82:433-40.

12. Weirather JL, Jeronimo SM, Gautam S, Sundar S, Kang M, Kurtz MA, et al. Serial quantitative PCR assay for detection, species discrimination, and quantification of Leishmania spp. in human samples. J Clin Microbiol. 2011;49:3892-904.

13. Souza LW, Souza SV, Botelho AC. Comparative analysis of the geographic distribution of the histopathological spectrum and Leishmania species of American cutaneous leishmaniasis in Brazil. An Bras Dermatol. 2012;87:369-74.

14. Mitropoulos P, Konidas P, Durkin-Konidas M. New World cutaneous leishmaniasis: updated review of current and future diagnosis and treatment. J Am Acad Dermatol. 2010;63:309-22.

15. Viana AG, Fraga CA, Batista Domingos PL, Bonan PR. Evaluation of myofibroblasts and its association with TGF- $\beta$ and IFN- $\gamma$ in lesions of patients with American tegumentary leishmaniasis. An Bras Dermatol. 2012;87:545-9.

16. Gontijo B, Carvalho MLR. Leishmaniose tegumentar americana. Rev Inst Med Trop. 2003;36:71-80.

17. Gomes CM, Morais 00, Leite AS, Soares KA, Motta Jde 0, Sampaio RN. Periungual leishmaniasis. An Bras Dermatol. 2012;87:148-9. 
18. Cannavò SP, Vaccaro M, Guarneri F. Leishmaniasis recidiva cutis. Int J Dermatol. 2000;39:205-6

19. Machado PR, Rosa ME, Costa D, Mignac M, Silva JS, Schriefer A, et al. Reappraisal of the immunopathogenesis of disseminated leishmaniasis: in situ and systemic immune response. Trans R Soc Trop Med Hyg. 2011;105:438-44.

20. Barral A, Costa JM, Bittencourt AL, Barral-Netto M, Carvalho EM. Polar and subpolar diffuse cutaneous leishmaniasis in Brazil: clinical and immunopathologic aspects. Int J Dermatol. 1995;34:474-9.

21. França-Costa J, Wanderley JL, Deolindo P, Zarattini JB, Costa J, Soong L, et al. Exposure of phosphatidylserine on Leishmania amazonensis isolates is associated with diffuse cutaneous leishmaniasis and parasite infectivity. PLoS One. 2012;7:e36595.

22. Guimarães LH, Machado PR, Lago EL, Morgan DJ, Schriefer A, Bacellar 0, et al. Atypical manifestations of tegumentary leishmaniasis in a transmission area of Leishmania braziliensis in the state of Bahia, Brazil. Trans R Soc Trop Med Hyg. 2009; 103:712-5.

23. Silveira FT, Lainson R, Corbett CE. Further observations on clinical, histopathological, and immunological features of borderline disseminated cutaneous leishmaniasis caused by Leishmania (Leishmania) amazonensis. Mem Inst 0swaldo Cruz. 2005;100:525-34.

24. Castellucci L, Menezes E, Oliveira J, Magalhaes A, Guimaraes LH, Lessa M, et al. IL6 -174 G/C promoter polymorphism influences susceptibility to mucosal but not localized cutaneous leishmaniasis in Brazil. J Infect Dis. 2006;194:519-27.

25. Motta AC, Lopes MA, Ito FA, Carlos-Bregni R, de Almeida OP, Roselino AM. Oral leishmaniasis: a clinicopathological study of 11 cases. Oral Dis. 2007;13:335-40.

26. Medeiros AR, Silva WA Jr, Roselino AM. DNA sequencing confirms the involvement of Leishmania (L.) amazonensis in American tegumentary leishmaniasis in the state of São Paulo, Brazil. Clinics (Sao Paulo). 2008;63:451-6.

27. Ben Salah A, Ben Alaya Bouafif N, Chlif S, Gharbi A, Bel Haj Hamida N, Zaatour A, et al. Risk factors of leishmanin-skin test positivity in transmission of Leishmania infantum in the center of Tunisia. Arch Inst Pasteur Tunis. 2003;80:17-27.

28. Alvar J, Aparicio P, Aseffa A, Den Boer M, Cañavate C, Dedet JP, et al. The relationship between leishmaniasis and AIDS: the second 10 years. Clin Microbiol Rev. 2008;21:334-59, table of contentes.

29. Castellano LR, Llaguno M, Silva MV, Machado JR, Correia D, Silva-Vergara ML, et al. Immunophenotyping of circulating T cells in a mucosal leishmaniasis patient coinfected with HIV. Rev Soc Bras Med Trop. 2011;44:520-1.

30. Roselino AM, Chociay MF, Costa RS, Machado AA, Figueiredo JF. (L.) chagasi in AIDS and visceral leishmaniasis (kala-azar) co-infection. Rev Inst Med Trop Sao Paulo. 2008:50:251-4.

31. Bari AU. Clinical spectrum of cutaneous leishmaniasis: an overview from Pakistan. Dermatol Online J. 2012;18:4.

32. Pereira MG. Epidemiologia: Teoria e Prática. 3 ed. Guanabara Koogan: Rio de Janeiro; 2000.

33. Garcia AL, Kindt A, Quispe-Tintaya KW, Bermudez H, Llanos A, Arevalo J, et al. American tegumentary leishmaniasis: antigen-gene polymorphism, taxonomy and clinical pleomorphism. Infect Genet Evol. 2005;5:109-16.

34. Reis Lde C, Brito ME, Almeida EL, Félix SM, Medeiros AC, Silva CJ, et al. Clinical, epidemiological and laboratory aspects of patients with American cutaneous leishmaniasis in the State of Pernambuco. Rev Soc Bras Med Trop. 2008;41:439-43.

35. Boggild AK, Ramos AP, Espinosa D, Valencia BM, Veland N, Miranda-Verastegui C, et al. Clinical and demographic stratification of test performance: a pooled analysis of five laboratory diagnostic methods for American cutaneous leishmaniasis. Am J Trop Med Hyg. 2010;83:345-50.

36. Pineda JA, Macías J, Morillas F, Fernández-Ochoa J, Cara J, de la Rosa R, et al. False-positive results of leishmanin skin test due to phenol-containing diluent. Trans R Soc Trop Med Hyg. 2001;95:173-4.

37. Fagundes A, Antônio L, Schubach A, Marzochi KB, Fagundes A. Comparison between in vivo measurement of the Montenegro skin test and paper recording. Int $\mathrm{J}$ Dermatol. 2012:51:618-9.

38. Szargiki R, Castro EA, Luz E, Kowalthuk W, Machado AM, Thomaz-Soccol V. Comparison of serological and parasitological methods for cutaneous leishmaniasis diagnosis in the state of Paraná, Brazil. Braz J Infect Dis. 2009;13:47-52.

39. Pomares C, Despierres L, del Giudice P, Delaunay P, Michel G, Ferrua B, et al. Western blot analysis as an aid for the diagnosis of cutaneous leishmaniasis due to Leishmania major. Trans R Soc Trop Med Hyg. 2012 Jul;106:452-4.

40. Zeyrek FY, Korkmaz M, Ozbel Y. Serodiagnosis of anthroponotic cutaneous leishmaniasis (ACL) caused by Leishmania tropica in Sanliurfa Province, Turkey, where ACL Is highly endemic. Clin Vaccine Immunol. 2007;14:1409-15.

41. Romero GA, de la Glória Orge Orge M, de Farias Guerra MV, Paes MG, de Oliveira Macêdo V, de Carvalho EM. Antibody response in patients with cutaneous leishmaniasis infected by Leishmania (Viannia) braziliensis or Leishmania (Viannia) guyanensis in Brazil. Acta Trop. 2005;93:49-56.
42. Daneshbod Y, Oryan A, Davarmanesh M, Shirian S, Negahban S, Aledavood A, et al. Clinical, histopathologic, and cytologic diagnosis of mucosal leishmaniasis and literature review. Arch Pathol Lab Med. 2011;135:478-82.

43. Hosseinzadeh M, Omidifar N, Lohrasb MH. Use of fine needle aspiration cytology in the diagnosis of cutaneous leishmaniasis: a comparison with the conventional scraping method. Trop Doct. 2012;42:112-3

44. Ameen M. Cutaneous leishmaniasis: advances in disease pathogenesis, diagnostics and therapeutics. Clin Exp Dermatol. 2010;35:699-705.

45. Lunedo SN, Thomaz-Soccol V, de Castro EA, Telles JE. Immunocytochemical and immunohistochemical methods as auxiliary techniques for histopathological diagnosis of cutaneous leishmaniasis. Acta Histochem. 2012;114:252-8.

46. Herwaldt BL. Leishmaniasis. Lancet. 1999;354:1191-9.

47. Viana AG, Domingos PL, Kaminagakura E, Botelho AC, Martelli H Jr, Bonan PR. Immunohistochemical profile of cytokeratins in pseudoepitheliomatous hyperplasia of cutaneous leishmaniasis. Int J Dermatol. 2011;50:1470-4.

48. Romero GA, Sampaio RN, Macedo Vde 0, Marsden PD. Sensitivity of a vacuum aspiratory culture technique for diagnosis of localized cutaneous leishmaniasis in an endemic area of Leishmania (Viannia) braziliensis transmission. Mem Inst Oswaldo Cruz. 1999;94:505-8.

49. Pavli A, Maltezou HC. Leishmaniasis, an emerging infection in travelers. Int J Infect Dis. 2010;14:e1032-9.

50. Boggild AK, Miranda-Verastegui C, Espinosa D, Arevalo J, Adaui V, Tulliano G, et al. Evaluation of a microculture method for isolation of Leishmania parasites from cutaneous lesions of patients in Peru. J Clin Microbiol. 2007;45:3680-4.

51. Boggild AK, Miranda-Verastegui C, Espinosa D, Arevalo J, Martinez-Medina D, Llanos-Cuentas A, et al. Optimization of microculture and evaluation of miniculture for the isolation of Leishmania parasites from cutaneous lesions in Peru. Am J Trop Med Hyg. 2008;79:847-52.

52. Allahverdiyev AM, Uzun S, Bagirova M, Durdu M, Memisoglu HR. A sensitive new microculture method for diagnosis of cutaneous leishmaniasis. Am J Trop Med Hyg. 2004;70:294-7.

53. Silva JG, Silva TM, Peloso Ede F, Machado-Coelho GL, Mayrink W, Ariosa MC, et al. Comparison among three polymerase chain reaction assays on detection of DNA from Leishmania in biological samples from patients with American cutaneous leishmaniasis. Rev Soc Bras Med Trop. 2012;45:257-9.

54. Roselino AM. Molecular biology in tropical dermatoses. An Bras Dermatol. 2008;83:187-203.

55. Miranda A, Saldaña A, González K, Paz H, Santamaría G, Samudio F, et al. Evaluation of $\mathrm{PCR}$ for cutaneous leishmaniasis diagnosis and species identification using filter paper samples in Panama, Central America. Trans R Soc Trop Med Hyg. 2012;106:544-8.

56. Graça GC, Volpini AC, Romero GA, Oliveira Neto MP, Hueb M, Porrozzi R, et al. Development and validation of PCR-based assays for diagnosis of American cutaneous leishmaniasis and identification of the parasite species. Mem Inst Oswaldo Cruz. 2012;107:664-74.

57. Kim OM, de Paula N, Roselino AM. Métodos diagnósticos em biologia molecular aplicada a dermatoses tropicais. In: Lupi 0, Cunha PR, editores. Rotinas de Diagnóstico e Tratamento da Sociedade Brasileira de Dermatologia. Rio de Janeiro: AC Farmacêutica; 2012. p.463-71.

58. Yehia L, Adib-Houreih M, Raslan WF, Kibbi AG, Loya A, Firooz A, et al. Molecular diagnosis of cutaneous leishmaniasis and species identification: analysis of 122 biopsies with varied parasite index. J Cutan Pathol. 2012;39:347-55.

59. Al-Jawabreh A, Schoenian G, Hamarsheh 0, Presber W. Clinical diagnosis of cutaneous leishmaniasis: a comparison study between standardized graded direct microscopy and ITS1-PCR of giemsa-stained smears. Acta Trop. 2006;99:55-61.

60. Schönian G, Kuhls K, Mauricio IL. Parasitology. Molecular approaches for a better understanding of the epidemiology and population genetics of Leishmania. Parasitology. 2011;138:405-25.
MAILING ADDRESS:
Ciro Martins Gomes
Hospital Universitário de Brasília SGAN 605,
Av. L2 Norte
70910-900 - Brasília - DF
Brazil
E-mail: ciromgomes@gmail.com

How to cite this article: Gomes CM, de Paula NA, de Morais OO, Soares KA, Roselino AM, Sampaio RNR. Complementary exams in the diagnosis of american tegumentary leishmaniasis. An Bras Dermatol. 2014;89(5):701-11. 